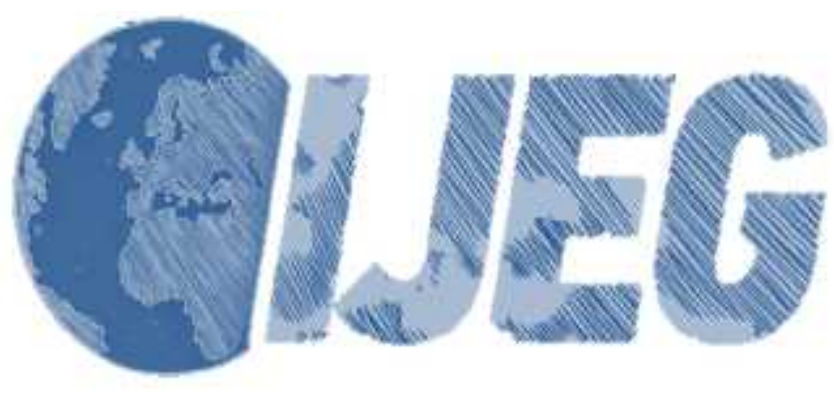

International Journal of Engineering and Geosciences (IJEG), Vol;2, Issue;01, pp. 1-8, February, 2017, ISSN 2548-0960, Turkey, DOI: $\underline{10.26833 / \text { ijeg.285770 }}$

\title{
LEAST COST PATH ALGORITHM DESIGN FOR HIGHWAY ROUTE SELECTION
}

\author{
Sarı, F., ${ }^{1 *}$ Şen, M., ${ }^{2}$ \\ ${ }^{1}$ Selcuk University, Çumra School of Applied Science, Management Information Systems Department \\ (fatihsari@selcuk.edu.tr) \\ ${ }^{2}$ The General Directorate of Cadastre and Land Registry, Konya, Turkey (mehmetsenxyzku@ yahoo.com)
}

*Corresponding Author, Received: 12/01/2017, Accepted: 30/01/2017

\begin{abstract}
Highway route design is a difficult process due to the complex structure of the environment. The topography and the natural geographical objects constitute an obstacle for highway constructions. On the other hand, the cost parameter and protecting the environment are main two issues which planners have to consider. Thus, the priorities of the highway routes should be decided according to the requirements and expectations. At this point, Least Cost Path Algorithm (LCPA) makes it possible to investigate least cost path for highway routes. This cost can be assigned as the cost of the constructions such as avoiding slope and swampy areas or an environmental object such as keeping the forests and not damaging to agricultural lands. When the cost parameter is decided, then LCPA can calculate the least cost path from origin point to destination. In this study, new highway routes are investigated for Konya city with economic, environmentally and hybrid approaches. The cost parameter and related surfaces are generated according to the highway construction requirements and then with LCPA, three different routes are calculated. The result maps are generated and the three approaches are compared for environmental and cost parameters.
\end{abstract}

Keywords: Least Cost Path Algorithm, Geographical Information Systems, Site Selection, Highway Projects 


\section{INTRODUCTION}

The highway planning has some conflicts between economic and environmental perspective. Considering the cost parameter can have negative effects to the environment and habitat due to the demonstrated forests, changed water resources directions, construction wastes, air pollution and noise. On the other hand, environmental oriented highway projects can increase the cost due to the higher slope and height values together with the increased length.

Due to the negative effects of highway projects to the environment, considerably, the cost of the projects is getting increased. The environmental and cost priorities of the highway projects must be considered when examining the most suitable highway routes. The environmental or cost oriented highway projects can be defined with Analytical Hierarchy Process (AHP).

AHP is the most mentioned methods in multi-criteria analysis and is a general term that refers to the applications used to determine the most suitable solution to the real problems by providing a selection from different data clusters (Arentze and Timmermans, 2000). For determining the most suitable highway locations, AHP includes flexible, effective and adjustable structure to provide user-defined solutions. Thus, the results can be adjusted, evaluated and measured both environmental and cost oriented approaches (Kara and Usul, 2012).

Beside AHP, least-cost path analysis (LCPA) algorithm is used to determine the route alternatives of highways. LCPA provides users to find a cheapest route that connects two locations with using a cost surface that is determined by considering multiple criteria (Hassan and Effat, 2013). The cost surface can be produced via Geographical Information Systems (GIS) and the cost criteria can be evaluated and weighted with AHP. Some of the studies on LCPA involve a selecting the fastest path with the least slope (Stefanakis and Kavouras, 1995), selecting three alternatives between destination and origin points (Hassan and Effat, 2013), determining arctic all weather road (Atkinson et al. 2005), optimal route from multiple destination and origin points (Lee and Stucky, 1998), multi-criteria based cost surfaces (Collischonn and Pliar, 2000) and (Douglas, 1994).

The studies show that suitable highway locations and routes should be determined with AHP and LCPA integration for real solutions. While AHP determines the most suitable locations, LCPA decides the route considering the weights of parameters that calculated with AHP. AHP provides cost surface to the LCPA such as environment, economic and social, thus, the routes can be determined with LCPA according to the desired parameter oriented approach.

In this study, the most suitable highway locations are determined with AHP and 3 routes are determined where new highway needed according to the environment, economic and AHP which is a combination environment and cost parameters.

\section{MATERIALS AND METHOD}

\subsection{Study Area}

The Konya city is located in the middle of Turkey and in the $40814 \mathrm{~km} 2$ area, it is the largest city of Turkey with its 31 districts (Figure 1). The population of Konya is 2.108.808 according to the 2014 Census (URL 1). A large amount of the population is settled in the city center and has a rapidly increasing population trend with $\% 6$.

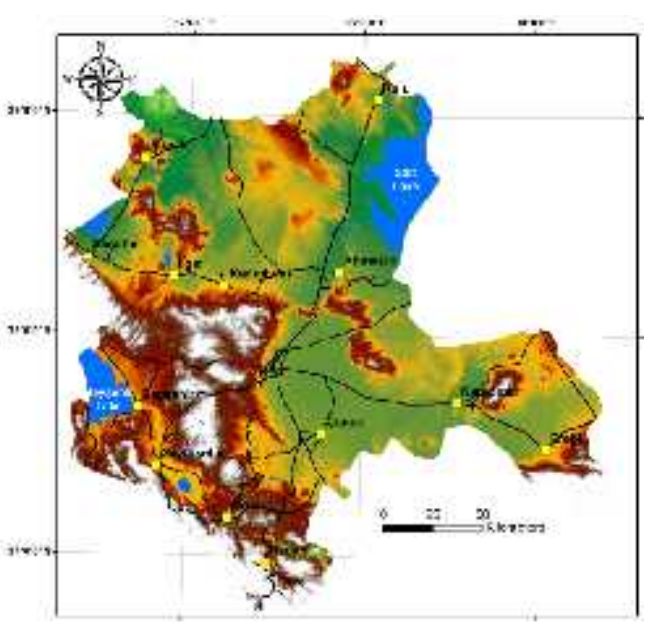

Figure 1 Study area

\subsection{Least Cost Path Algorithms}

In practice, the majority of routing methods are based on least-cost algorithms. The link cost is defined on both directions between each pair of nodes. Several leastcost-path algorithms have been developed for packetswitched networks. In particular, Dijkstra's algorithm and the Bellman-Ford algorithm are the most effective and widely used algorithms (Nader, 2006).

\subsection{The Dijkstra algorithm}

Dijkstra's algorithm is a centralized routing algorithm that maintains information in a central location. The objective is to find the least-cost path from a specified source node to all other nodes. This algorithm determines least-cost paths from a origin node to a destination node by optimizing the cost in multiple iterations. Dijkstra's algorithm is as follows : (Rees, 2004),

1. Assign a definite cost of zero to the target cell.

2. Identify all the neighbouring cells to the target cell and place them in the list of 'active' cells. For each of these cells, calculate and assign the cost of reaching the target cell, and assign a pointer that points to the target cell;

3. Find the cell in the list that has the lowest cost, Name this cell as $\boldsymbol{C}$ and the cost as $\boldsymbol{k}$; 
4. Determine all the neighbouring cells of $\boldsymbol{C}$ as $\boldsymbol{S}$. For each cell $C^{\prime}$ in $S$, calculate the cost $\boldsymbol{l}$ of moving to C.

4.1. If $\boldsymbol{C}$ is not included of the list, add it to the list with a cost $\boldsymbol{k}+\boldsymbol{l}$ and a pointer that points to $\boldsymbol{C}$.

4.2. If $\boldsymbol{C}$ is already a member of the list, compare the value of $\boldsymbol{k}+\boldsymbol{l}$ with the provisional cost of this cell. If $\boldsymbol{k}+\boldsymbol{l}$ is greater than or equal to the provisional cost, do nothing. However, if $\boldsymbol{k}+$ $\boldsymbol{l}$ is less than the provisional cost, change the attributes of the cell $\mathrm{C}$ so that its cost is now $\boldsymbol{k}+\boldsymbol{l}$ and its pointer now points to the cell $\mathrm{C}$.

5. Change the attributes of the cell $\mathrm{C}$ from provisional to definite, and remove it from the list.

6. Repeat from (3) until the list is empty (Rees, 2004), (Dijkstra, 1959).

\subsection{How cost distance works (ArcGIS Example)}

The cost to travel between one node and the next is dependent on the spatial orientation of the nodes. How the cells are connected also impacts the travel cost (URL 2). The topology is being important in this cost calculation. When moving from a cell to one of its four directly connected neighbours, the cost can be calculated as;

$a 1=(\operatorname{cost} 1+\cos t 2) / 2$

where:

cost1, The cost of cell 1

cost2, The cost of cell 2

a1, The total cost of the link from cell 1 to cell 2

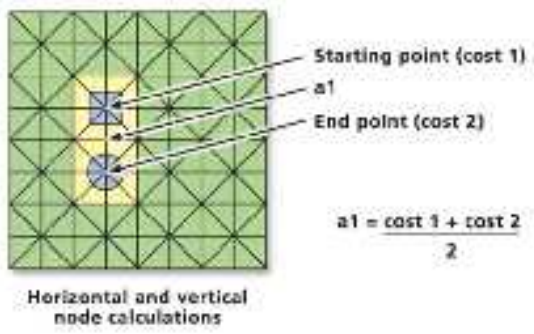

Figure 2 Adjacent nodes

The accumulative cost can be determined by the following formula:

accum_cost $=a 1+(\cos t 2+\cos t 3) / 2$

where:

cost2; The cost of cell 2

cost3; The cost of cell 3

a2; The cost of moving from cell 2 to 3 accum_cost; The accumulative cost to move into cell 3 from cell 1

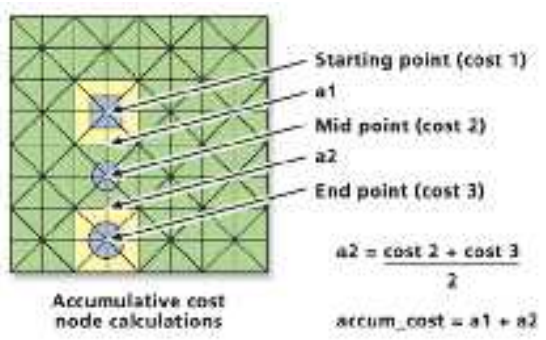

Figure 3 Perpendicular nodes

If the movement is diagonal, the cost to travel over the link can be calculated with; (1.41421 is square root of 2);

$a 1=1.414214(\cos t 3+\cos t 2) / 2$

When determining the accumulative cost for diagonal movement, the following formula must be used

accum_cost $=a 1+1.414214(\cos t 2+\cos t 3) / 2$

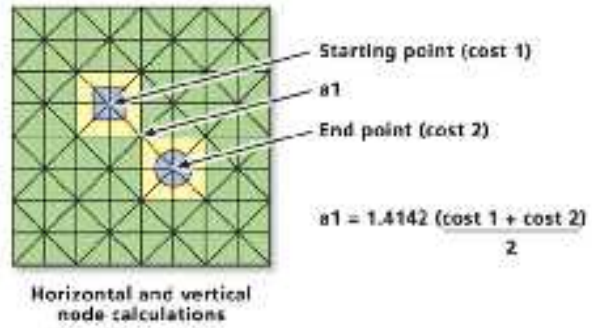

Figure 4 Diagonal nodes

Creating a cost-distance raster using graph theory can be viewed as an attempt to identify the lowest-cost cell. It is an iterative process that begins with the source cells. The goal of each cell is to be assigned quickly to the output cost-distance raster (URL 2).
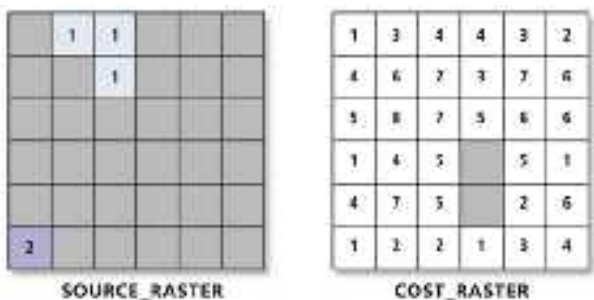

DVulie a NCOATA

Figure 5 Accumulative cost cells

In the first iteration, the source cells are identified and assigned 0 since there is no accumulative cost to return to themselves. Next, all the source cell's neighbours are activated, and a cost is assigned to the links between the source cell nodes and the neighbouring cells' nodes using the above accumulative cost formulas. To be 
assigned to the output raster, a cell must have the next least-cost path to a source (URL 2).

The accumulative cost values are arranged in a list from the lowest accumulative cost to the highest (Figure 6).
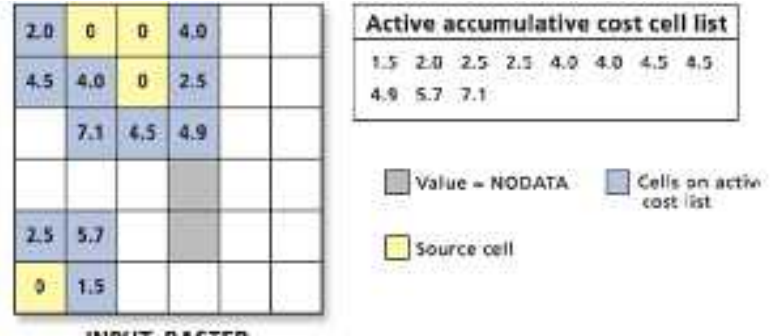

Figure 6 Cost calculation first stage

The lowest cost cell is chosen from the active accumulative cost cell list, and the value for that cell location is assigned to the output cost-distance raster. The list of active cells expands to include the neighbours of the chosen cell, because those cells now have a way to reach a source. Only those cells that can possibly reach a source can be active in the list. The cost to move into these cells is calculated using the accumulative cost formulas (URL 2).
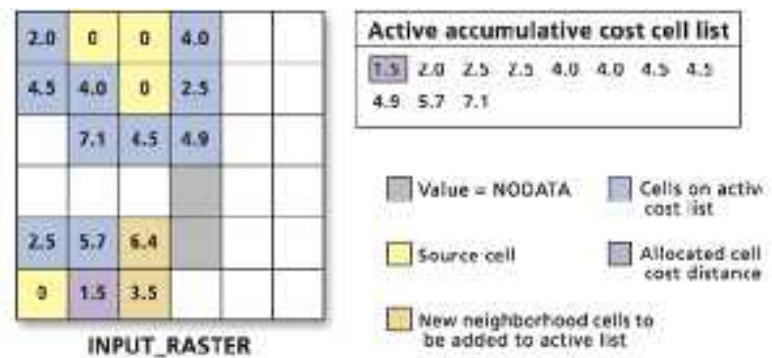

Figure 7 Cost calculation second stage

Again, the active cell on the list with the lowest cost is chosen, the neighbourhood is expanded, the new costs are calculated, and the new cost cells are added to the active list. Source cells do not have to be connected. All disconnected sources contribute equally to the active list. Only the cell with the lowest accumulative cost is chosen and expanded, regardless of the source to which it will be allocated (URL 2).
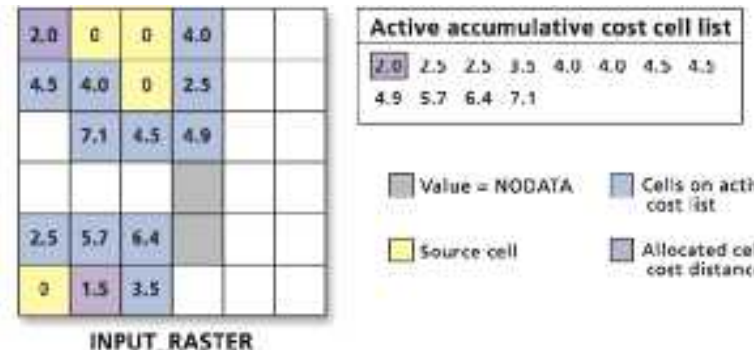

$4.9 \quad 5.7 \quad 6.4 \quad 7.1$

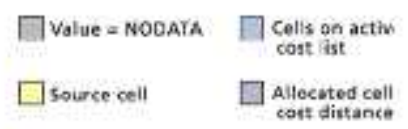

Figure 8 Cost calculation third stage
This allocation process continues. Furthermore, cells on the active list are updated if a new, cheaper route is created by the addition of new cell locations to the output raster (URL 2).

\begin{tabular}{|c|c|c|c|c|c|c|}
\hline 2.0 & 0 & 0 & 4.0 & 6.7 & 9.2 & Active accumulative cost cell list \\
\hline 4.5 & 4.0 & o & 2.5 & 7.5 & 13.5 & 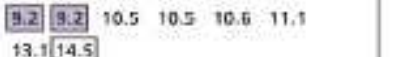 \\
\hline 8.0 & 7.1 & 4.5 & 4.9 & 8.9 & 14.5 & \\
\hline 5.0 & 7.5 & 16.5 & & 10.6 & 9.2 & $\square$ value - NODATA \\
\hline 2.5 & 5.7 & 6.4 & & 2.1 & 11,1 & $\square$ source cell \\
\hline 0 & 1.5 & 3.5 & 5.0 & 7.0 & 10.5 & \\
\hline
\end{tabular}

Figure 9 Cost calculation final stage

While the output cost distance raster identifies the accumulative cost for each cell to return to the closest source location, it does not show which source cell to return to or how to get there. The Cost Back Link process returns a direction raster as output, providing what is essentially a road map that identifies the route to take from any cell, along the least-cost path, back to the nearest source (URL 3).

The algorithm for computing the back link raster assigns a code to each cell. The code is a sequence of integers from 0 to 8 . The value 0 is used to represent the source locations, since they have essentially already reached the goal (the source). The values 1 through 8 encode the direction in a clockwise manner starting from the right. Following is the default symbology applied to the directional output, accompanied by an arrow diagram matching directional arrows to the color symbology (URL 3):
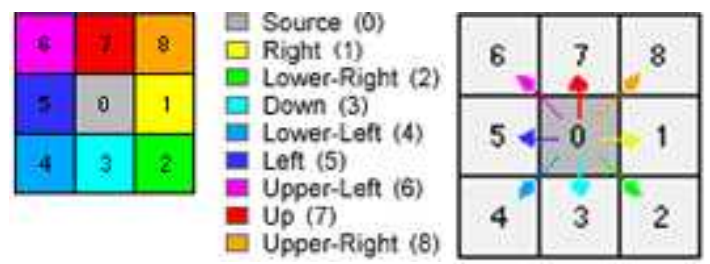

Figure 10 Back link raster calculation

\subsection{AHP Application}

The criteria selection reflects the requirements, expectations and restrictions of highway constructions. The main criteria of highway projects can be divided into two categories as like environment and economic. Each criterion will be weighted with AHP to decide the most suitability highway routes according to the defined scores. Evaluating for economic criteria, highway routes are expected to be in quite flat lands from avoiding excavation costs. Height criterion is related to slope criterion and considering the climate conditions, it 
defines the characterization of highway route. If a highway has a high height, it will be negatively affected from climate conditions like perception, snow, wind and ice in winter. Height is also increasing the excavation costs and the slope of the highway route. This mean increased fuel consumption, particularly for transportation vehicles.

The environmental criteria are critical for highway routes to protect the environment and habitat. Highway constructions can destroy the forest and fertile agricultural lands. Addition to this, the habitats and migration routes of animals can be damaged due to the vehicle flow, sound, exhaust emissions and related air pollutants. First of all, the purpose of the project aim must be demonstrated that the priority will be protecting the environment or the cost. AHP can define this distinction easily with the pair-wise comparison matrix. (Saaty, 1977). The procedure outlined by Saaty (1977, 1980) scales the importance of each criterion, from 1 to 9 relatively.

The pair-wise comparison square matrix is defined for main-criteria, criteria and sub -criteria to determine the weights. The diagonal elements of the comparison matrix are 1. Each element of the comparison matrix is divided to the sum of the own column sum to generate a normalized matrix with Formula 1.

$a_{i j}^{1}=\frac{a_{i j}}{\sum_{i=1}^{n} a_{i j}}$

Each column of the normalized matrix sum is equal to 1 . Then, each row sum of the normalized matrix is divided to the matrix order. The average of the sum represents the weights of cach criterion in pair.wise comparison matrix (Formula 2).

$\mathbf{u}_{i}=\left(\frac{1}{n}\right) \sum_{i=1}^{n} a_{i j}^{\prime}(i, j=1,2,3, \ldots, n)$

The consistency of the pair-wise comparison matrix must be calculated to decide the criteria comparisons are consistent or not. The assigned preference values are synthesized to determine a ranking of the relevant factors in terms of a numerical value which is equivalent to the weights of each parameter. Therefore, the eigenvalues and eigenvectors of the square pair-wise comparison matrix revealing important details about patterns in the data matrix are calculated. It is regarded sufficient to calculate only the eigenvector resulting from the largest eigenvalue since this eigenvector contains enough information to the relative priorities of the parameters being considered (Saaty\& Vargas 1991).

Consistency Index (CI) is one of the methods to define the consistency coefficient of pair-wise comparison matrix. Cr is calculated with Formula 3 (Saaty, 1994).

$C I=\frac{\Lambda_{\text {amax }}-n}{n-1}$

Calculating consistency index depends the max (eigen value) value with Fotnulla 4 (Saaty, 1994).

$K_{\lambda \max }=\frac{1}{n} \sum_{i=1}^{n}\left[\frac{\sum_{j=1}^{n} n_{i j} n}{n_{i}}\right]$
Addition to this, random index (RI) value must be calculated to determine consistency index. For each matrix order, RI values are given in Table 1.

Table 1. RI values according to the matrix order

\begin{tabular}{|c|c|c|c|c|c|c|c|c|c|c|}
\hline $\mathbf{n}$ & $\mathbf{1}$ & $\mathbf{2}$ & $\mathbf{3}$ & $\mathbf{4}$ & $\mathbf{5}$ & $\mathbf{6}$ & $\mathbf{7}$ & $\mathbf{8}$ & $\mathbf{9}$ & $\mathbf{1 0}$ \\
\hline $\mathbf{R I}$ & 0 & 0 & 0,58 & 0,90 & 1,12 & 1,24 & 1,32 & 1,41 & 1,45 & 1,49 \\
\hline
\end{tabular}

After calculating the CI and RI, consistency ratio (CR) can be calculated with Formula 5. If CR exceeds 0.1, based on expert knowledge and experience, Saaty\& Vargas (1991) recommend a revision of the pair-wise cornparison matrix with different values. (Saaty, 1980).

$C R=\frac{C I}{B I}$

Several criteria should be considered when selecting highway routes. In this study, 7 criteria are considered within 2 main criteria, environmental and economic. Slope, distance from highways, height and population criteria are included in economic main criteria which are affecting the cost of the highway projects. Distance from settlements, land use and geology criteria are related to the respect to the environment (Figure 11).

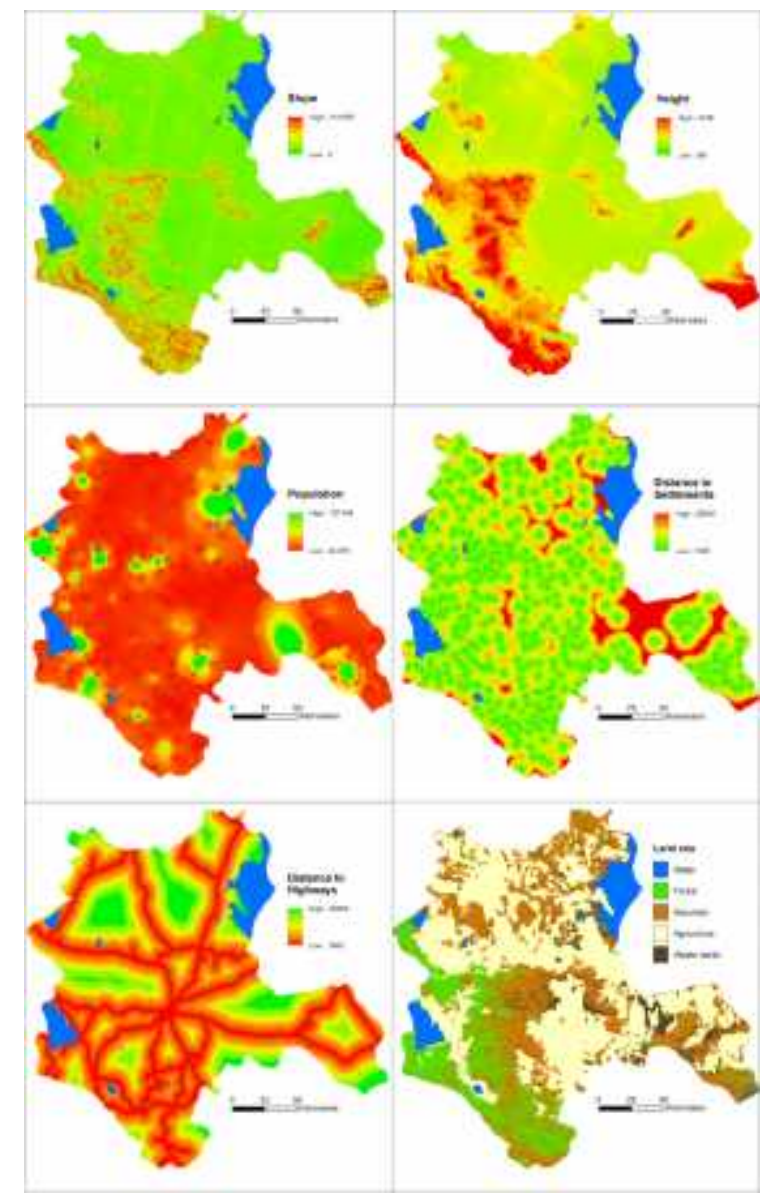

Figure 11 Criteria maps 


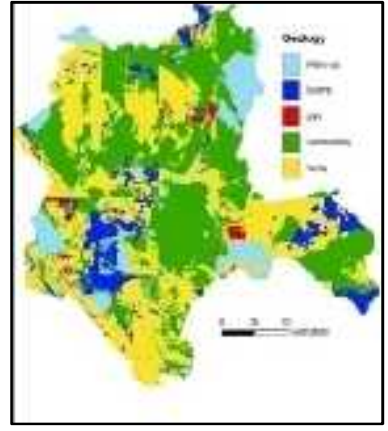

Figure 11 Criteria maps

Each criterion is mapped and then reclassified with ArcGIS software according to the defined classes which are illustrated in Figure 11. These are defined as subcriteria and AHP weights. are calculated for the maincriteria, criteria and sub-criteria In first stage, environmental and economic main criteria are weighted with pair-wise comparison matrix which is given in Table 3,4.

Table 2. Main criteria weights

\begin{tabular}{cccc}
\hline$A$ & $C_{1}$ & $C_{2}$ & $W$ \\
\hline$C_{1}$ & 1 & 0.6666 & 0.40 \\
$C_{2}$ & $1 / 0.6666$ & 1 & 0.60 \\
\hline
\end{tabular}

$\mathrm{A}=$ Highway suitability $\mathrm{C} 1=$ Environmental, $\mathrm{C} 2=$ Economic, $\mathrm{CR}=0.0000, \mathrm{~W}=\mathrm{Weights}$ of $\mathrm{C} 1$ and $\mathrm{C} 2$

The main-criteria weights are calculated as 0,40 for $\mathrm{C} 1$ and 0,60 for $\mathrm{C} 2$ (Table 2). Therefore, economic criteria are more important than environmental criteria for this study.

In second stage, criteria weights are calculated separately according to the main-criteria. The $\mathrm{CR}$ values of all comparisons are lower than 0.10 , which indicated that the use of the weights are suitable (Table 3,4).

Table 3.Economic criteria weights

\begin{tabular}{ccccc}
\hline$B_{1}$ & $C_{3}$ & $C_{4}$ & $C_{5}$ & $W$ \\
\hline$C_{3}$ & 1 & 2 & 2 & 0.49981 \\
$C_{4}$ & $1 / 2$ & 1 & 1.1 & 0.25804 \\
$C_{5}$ & $1 / 2$ & $1 / 1.1$ & 1 & 0.24215 \\
\hline
\end{tabular}

$\mathrm{B} 1=$ Economic criteria, $\mathrm{C} 3=$ Slope,

$\mathrm{C} 4=$ Height, $\mathrm{C} 5=$ Geology, $\mathrm{CR}=0,0009$

$\mathrm{W}=$ Weights of $\mathrm{C} 3, \mathrm{C} 4$ and $\mathrm{C} 5$

Table 4.Environmental criteria weights

\begin{tabular}{cccccc}
\hline$B_{2}$ & $C_{6}$ & $C_{7}$ & $C_{8}$ & $C_{9}$ & $W$ \\
\hline$C_{6}$ & 1 & 2.5 & 2.2 & 1.6 & 0.40156 \\
$C_{7}$ & $1 / 2.5$ & 1 & 1.2 & 2.2 & 0.24719 \\
$C_{8}$ & $1 / 2.2$ & $1 / 1.2$ & 1 & 1.4 & 0.18646 \\
$C_{9}$ & $1 / 1.6$ & $1 / 2.2$ & $1 / 1.4$ & 1 & 0.16479 \\
\hline
\end{tabular}

B2= Environmental criteria, C6= Land, C7=Population,
$\mathrm{C} 8=$ Distance to settlements $\mathrm{C} 9=$ distance to highways, $\mathrm{CR}=0,0498 \mathrm{~W}=$ Weights of $\mathrm{C} 6, \mathrm{C} 7, \mathrm{C} 8$ and $\mathrm{C} 9$

\subsection{Least-Cost Path Algorithm Application}

Least Cost path Algorithm is generated by ArcGIS software with using spatial analyst extension. Totally, 3 routes are calculated with LCPA which are determined the most highway required locations with AHP (Figure 12). There are 3 cost surfaces is determined for LCPA to calculate the least cost path between origin and destination points. The origin and destination points are specified with calculating the intersection of existing highways in districts.

The least cost paths are determined for economic, environmental and AHP calculations separately. The weights that are determined with AHP (Table 2,3,4) are used to generate the cost surfaces. The cost surfaces are calculated as follows,

Economic cost surface $=[(0.49981$ X Slope $)+$ $(0.25804 \times$ Height $)+(0.24215 \times$ Geology $)]$

Environmental cost surface $=[(0.40156 \times$ Land use $)+$ $(0.24719 \times \quad$ Population $)+(0.18646 \mathrm{x}$ Dist_from_settlements) $\quad+\quad(0.16479 \quad \mathrm{x}$ Dist_from_highways)]

AHP cost surface $=[(0.30 \mathrm{X}$ Slope $)+(0.1548 \mathrm{x}$ Height $)+(0.145 \times$ Geology $)+(0.1606 \times$ Land use $)+$ $(0.0988 \quad \mathrm{x}$ Population $)+(0.074 \mathrm{x}$ Dist_from_settlements $) \quad+\quad(0.0658 \quad \mathrm{x}$ Dist_from_highways)]

Deciding the most suitable path requires a comparison of the routes according to the length, slope, land use and population. The AHP routes can be called as hybrid route because it combines both economic and environmental criteria together. AHP route is calculated with \% 60 economic and \%40 environmental criteria. According to the aim, these weights can be changed considering the requirements as like cost or environment oriented highway constructions. The AHP, Economic and Environment oriented cost surfaces are given in Figure 12. 


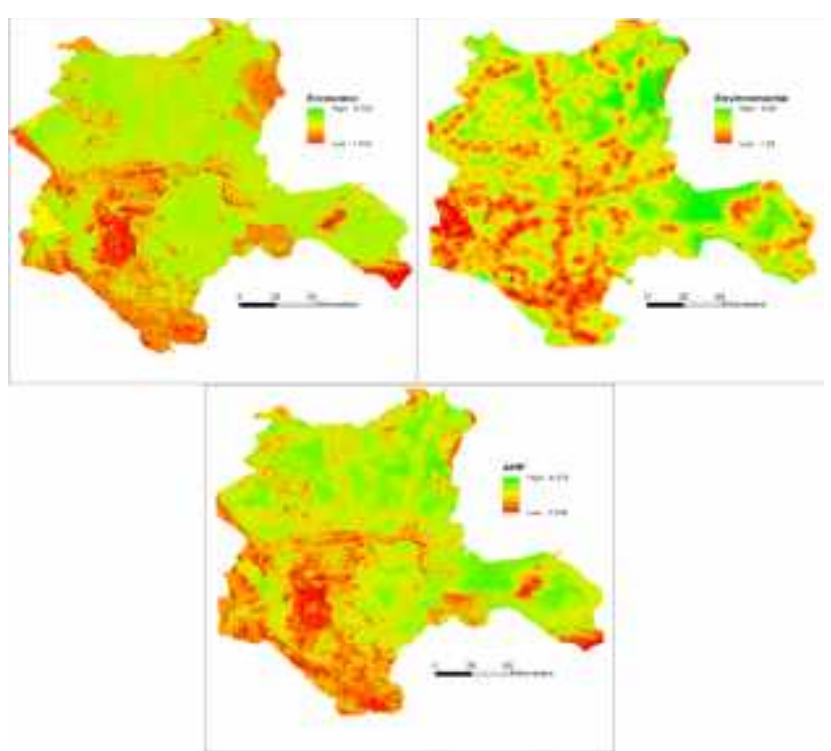

Figure 12 Cost surfaces for economic, environment and AHP

The origin and destination points are defined considering the existing highways and intersection of highways which connect the districts. The back link raster must be generated to be able to calculate the least cost paths. The back link rasters include the directions of raster cells to each other by considering the origin and destination points. The rasters are given in Figure 13.

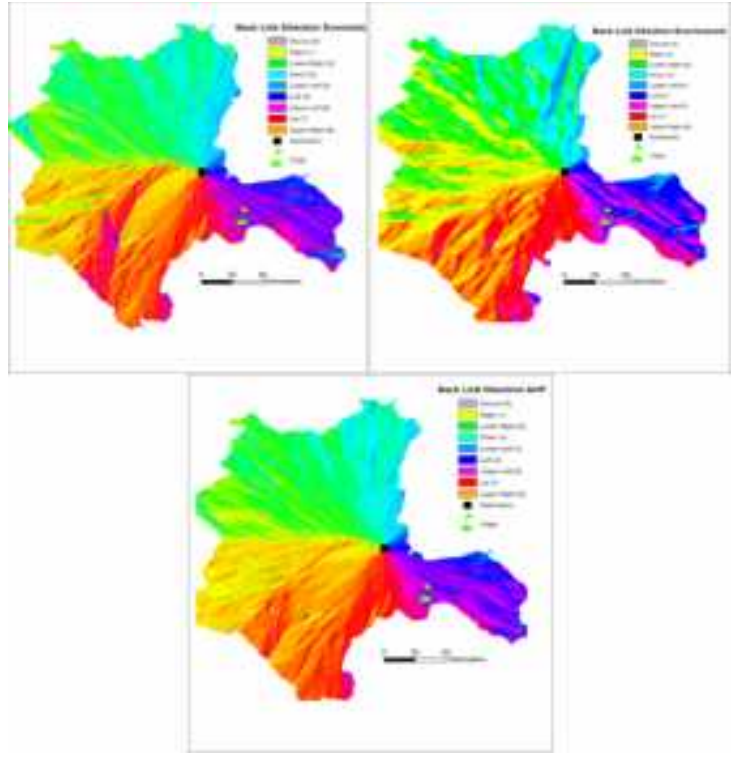

Figure 13 Back link rasters for economic, environment and AHP

The determined suitable locations are used to generate LCPA paths for economic, environmental and AHP oriented approach (Figure 14). There are 3 LCPA routes are determined for mentioned location. The routes tend to be close each other considering the homogeneous geographical distributions of the criteria.

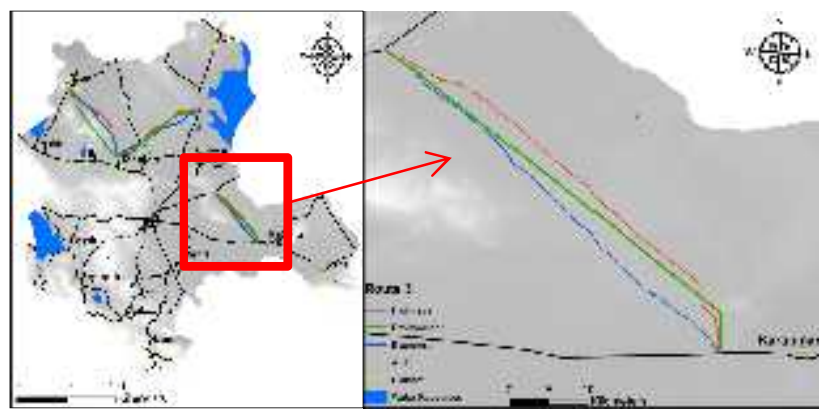

Figure 14 LCPA routes

Profiles of the routes are generated via ArcGIS software to compare the heights of routes. The profiles are given in Figure 15 for Route 1, Route 2 and Route 3). The vertical axis of the graph represents the altitude (meter) and the horizontal axis represents the length (kilometer) of the determined route.

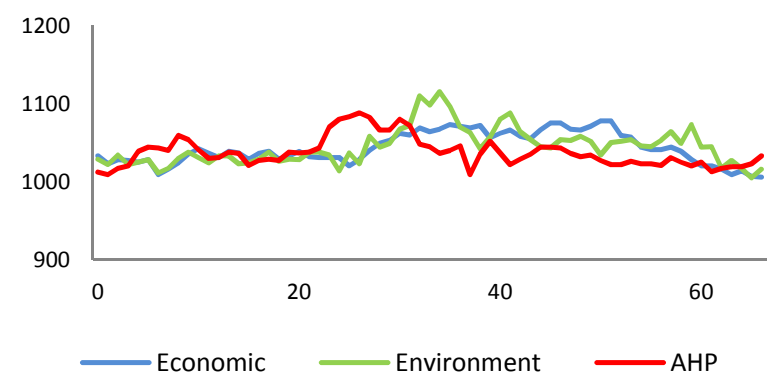

Figure 15 Height profiles of the LCPA routes

\section{RESULTS}

The results show that determined most suitable highway locations are quite enough to decide highway routes together with LCPA integration. Instead of deciding cost oriented routes, the hybrid AHP routes are more appropriate for projects. However, the suitable highway locations should be investigated with environment oriented routes and then compared with economic oriented routes.

The routes should be investigated and minor modifying can be processed on highway routes. Especially in economic routes, the LCPA determined the routes within less slope and height. Thus, the routes can be intersected with the water collect and flow lines of the mountains and hills. This will increase the cost due to the new construction requirement such as culverts and drainage structures. The crossroads and intersection points according to the settlements can be easily decided by an investigation process on determined highway routes. 


\section{REFERENCES}

Arentze, T. A. and Timmermans, H. J. P., 2000. ALBATROSS: A Learning-based Transportation Oriented Simulation System. EIRASS, Eindhoven University of Technology, The Netherlands.

Atkinson, D.M., Deadman, P., Dudycha, D., Traynor, S., 2005. Multi-criteria evaluation and least cost path analysis for an arctic all-weather road. Appl. Geogr. 25, 287-307.

Collischonn, W., Pilar, J.V., 2000. A directional dependent least-cost path algorithm for roads and canals. Int. J. Geogr. Inform. Sci. 14 (4), 397-406.

Dijkstra, E.W., 1959. A note on two problems in connection

with graphs. Numerische Mathematik 1, 269-271.

Douglas, D.H., 1994. Least cost path in GIS using an accumulated cost surface and slope lines. Cartographica 31 (3), 37-51.

Hassan, O., Effat, H., (2013). Designing and evaluation of three alternatives highway routes using the Analytical Hierarchy Process and the least -cost path analysis, application in Sinai Peninsula, Egypt. The Egyptian Journal of Remote Sensing and Space Sciences, 16, 141151

Kara, F., Usul, N., 2012. Highway Route Design Through The Use Of GIS AndMulticriteria Analysis: A Case Study Of Istanbul. Ozean Journal of Applied Sciences 5(1), 71-84.

Lee, J., Stucky, D., 1998. On applying viewshed analysis for determining least-cost paths on digital elevation models. Int. J. Geogr. Inform. Systems 12 (8), 891-905.

Nader, M, F., 2006. Computers and Communication Networks, Prentice Hall, ISBN-13: 978-0131389106.

Rees, W.G., 2004. Least cost paths in mountainous terrain. Computers \& Geosciences, 30, 203-209.
Saaty, T. L., 1977. A scaling method for priorities in hierarchical structures. Journal of Mathematical Psychology, 15, 234-281.

Saaty, T. L. 1980. The analytical hierarchy process. New York: Wiley.

Saaty, T. L. 1994. Fundamentals of Decision Making and Priority Theory With The Analytical Hierarchy Process, RWS Publ. Pittsburg, ,s 69-84, 1994.

Saaty, T.L., Vargas, L.G., 1991. Prediction, Projection and Forecasting. Kluwer Academic Publishers, Dordrecht, $251 \mathrm{pp}$.

Stefanakis, E., Kavouras, M., 1995.On the determination of the optimum path in space. In: Proceedings of the European Conference on Spatial Information Theory, COSIT 95, Lecture Notes in Computer Science. Springer, Berlin.

URL 1, Turkish Statistical Institute Official website, http://www.tuik.gov.tr/Start.do , , (Last visited 11.01.2016).

URL 2 Arcgis Help Center, http://desktop.arcgis.com/en/arcmap/10.3/tools/spatialanalyst-toolbox/how-the-cost-distance-toolswork.htm\#ESRI_SECTION1_F6B0C27F739748A5BD6 C8E4BB651E453

URL 3 Arcgis Help Center, http://desktop.arcgis.com/en/arcmap/10.3/tools/spatialanalyst-toolbox/understanding-cost-distanceanalysis.htm

Copyright (C) International Journal of Engineering and Geosciences (IJEG). All rights reserved, including the making of copies unless permission is obtained from the copyright proprietors. 